\title{
O Princípio Poluidor Pagador e sua Aplicabilidade no Direito Brasileiro
}

\section{The Poluter Pays Principle and its Applicability According to the Brazilian Law.}

\section{SURGIK, A.C. S. ${ }^{1}$ e MACHADO, P.A.L. ${ }^{2}$}

${ }^{1}$ Doutoranda em Ecologia do Instituto Nacional de Pesquisas da Amazônia, INPA(AM)

R. Sebastião Paraná, 1073. Curitiba - PR, CEP 80320-070. carolinasurgik@hotmail.com ${ }^{2}$ Professor da UNESP, Campus de Rio Claro - SP e da Universidade de Limoges, França. R.Barão de Piracicamirim, 787, apto 102. Piracicaba - SP, CEP 13416-150

\section{RESUMO}

$\mathrm{O}$ artigo traz a revisão conceitual do princípio poluidor-pagador, com sua atual abrangência, características, críticas e dificuldades de aplicação. Foi feita a análise da responsabilidade pela poluição no Brasil, enfocando sua natureza jurídica e tipos de poluição abrangidas.

Palavras-chave: Direito, meio ambiente, poluição, responsabilidade.

\section{SUMMARY}

The article brings a conceptual review of polluter pays principle, with its current reachs, characteristics, critics and difficulties of enforcement. The analysis was made on the responsibility for pollution in Brazil, focusing its legal nature and all kinds of pollution encompassed.

Keywords : Law, environment, pollution, responsibility. 


\section{Introdução}

Os chamados princípios jurídico-ambientais são concepções teóricas básicas que orientam o Direito Ambiental. São uma forma de direcionar o legislador na busca de uma política ambiental racional e harmônica, influenciando na interpretação e composição de aspectos obscuros deste ramo do Direito. Entre estes princípios, encontrase o princípio poluidor-pagador.

Sob a óptica deste princípio, o causador da poluição deve arcar com os custos necessários à diminuição, eliminação ou neutralização dos danos. Impõe-se que o sujeito econômico poluidor sane as externalidades negativas produzidas por sua atividade, que são sofridas pela coletividade.

\section{Definição, características e abrangência do princípio poluidor-pagador .}

A OECD (Organization for Economic Co-operation and Development) foi quem primeiro recomendou a adoção do princípio poluidor-pagador em seus países membros em 1972.

No Guia sobre o princípio (OECD, 1975), há a definição inicialmente adotada pela OECD. "O poluidor deve arcar com os custos de controle de poluição e medidas de prevenção exigidas pela autoridade pública, independentemente se estes custos são o resultado da imposição de alguma taxa de poluição, ou se é debitado por algum outro mecanismo econômico satisfatório, ou ainda, se é uma resposta a algum regulamento direto de redução de poluição obrigatória." O objetivo é o de garantir um estado aceitável de emissão, definido pelas autoridades públicas. Os custos privados dos bens e serviços devem refletir a escassez ambiental usada na sua produção, encorajando seu uso racional. Portanto é, fundamentalmente, um princípio de alocação de custos.

Para este princípio, não importa se os custos ambientais totais ou parciais são refletidos nos preços finais para consumidores. Isto não fere a essência do princípio. $\mathrm{O}$ importante, é que o poluidor deve ser a primeira parte a arcar com o pagamento, afinal, é ele quem tem completo controle de decisão sobre o processo de fabricação de sua atividade econômica. No Brasil, no entanto, deve haver completo respeito ao Código do Consumidor, conforme exposto adiante.

De acordo com a definição da OECD (1975), o poluidor-pagador não era, inicialmente, um princípio que pretendia interiorizar completamente os custos de poluição e não envolvia compensação por danos causados por poluição. O poluidor devia ser encarregado com o custo de qualquer prevenção de poluição e medidas de controle, preventivas e/ou de restauração determinados pelas autoridades públicas. Mas nada impedia que um país obrigasse o poluidor também a compensar os poluídos pelo dano 
resultante da poluição residual (quando as medidas levadas pelas autoridades públicas não implicam uma proibição total em emissão).

No entanto, de acordo com as correntes mais modernas e as novas realidades ambientais, hoje o princípio tem uma maior extensão, indo além dos custos de prevenção e controle citados em 1972. Houve um crescente interesse em solucionar problemas não visualizados na época e que não vão contra o poluidor-pagador. É o caso da ajuda financeira em esforços necessários em escala mundial (exemplo: a proteção da camada de ozônio) e também a ajuda a poluidores que previnem a mais do que as medidas exigidas pelas autoridades (ENVIRONMENT DIRECTORATE, 1992).

A internalização dos custos também foi ampliada sensivelmente, passando da obrigação de cobrir os custos parciais, para uma obrigação de custos quase completa, com o uso crescente de mecanismos de compensação e multas. Hoje é admitida a inclusão de custos de medidas administrativas, como pagamentos de análises e controle de sistemas. Uma outra extensão bastante importante, foi a possibilidade de inclusão do custo do dano residual em casos de danos significantes. São os casos onde o poluidor compensa as vítimas mesmo utilizando-se de sua quota de emissão permitida.

Além disso, desde 1988, é possível a inclusão dos custos de medidas e controle de poluição acidental, incluindo reabilitar o ambiente e a possibilidade de compensação a proprietários próximos às instalações afetadas pelo risco. No entanto, o poluidor deve arcar somente com o custo de "medidas razoáveis", de modo que tenha uma instalação responsável. Outra extensão atual é a de o poluidor poder compartilhar seus custos através de seguros, pois capitais de compensação financiados por seguradoras não vão contra os objetivos e a natureza do princípio em questão (ENVIRONMENT DIRECTORATE, 1992). Ressalte-se, no entanto, que estes seguros permitidos na Europa devem ser vistos com cautela. Tal sistema pode sanar o problema ambiental imediato, mas não atinge o objetivo maior do poluidor-pagador: a conscientização ambiental e a desincentivo a novas poluições.

Nota-se, portanto, a necessidade de sempre determinar a abrangência do princípio em cada país. Conforme a interpretação, o poluidor também terá o ônus de pagar pelos danos causados mesmo tendo respeitado os padrões dos órgãos ambientais. Mesmo nos países onde isso não é explícito, tem sido aceito esse posicionamento nos casos de danos sensíveis (MARTINEZ Jr, 2000).

A execução do princípio pode ser feita pelos meios de processos e padrões de produção, por instrumentos de regulamentação individual, proibição de cargas de poluição com taxas ou cobrança, podendo ser combinados e/ou somados. A legitimidade para esta realização é apenas das autoridades públicas e a escolha do instrumento de execução é de particular importância para a efetividade da política (OECD, 1975). 
Pela definição inicial da OECD, o poluidor-pagador é basicamente um princípio anti-subsídio, pois são os poluidores que devem arcar com os custos da poluição. Subsídios seriam aceitos apenas como exceção ao princípio, rigorosamente regulada pela Organização. Seriam permitidos apenas para atividades em sérias dificuldades, por um período de adaptação à nova política ambiental e, ainda, se não gerassem distorções no comércio internacional. No entanto, a própria OECD em estudo mais recente (OECD 1989 apud ALMEIDA, 1998) reconhece a vasta utilização de subsídios em seus Países Membros. Como destaca SMETS (1997), até mesmo na França há subsídios públicos para construir "cadeias de purificação". Este equilíbrio global entre ajudas públicas e impostos foi utilizado nas Agências de Água na França.

Note-se que há uma estreita relação entre política ambiental e política socioeconômica global de uma região ou país. Na própria explicação dos limites do princípio, a OECD (1975) informa que ajudas para estimular desenvolvimento e experimentação de novas tecnologias de controle e abatimento de poluição não são incompatíveis com o poluidor-pagador. Este posicionamento facilita a introdução implícita de subsídios no sistema.

Para SMETS (1997), o poluidor-pagador foi finalizado como princípio econômico fundado em uma análise de custo marginal e não como princípio de eqüidade, representando o papel errôneo de um obstáculo absoluto para concessões. Este princípio é apresentado atualmente por definições legais simplistas e, em certos casos, é considerado um obstáculo para a perseguição das políticas eficientes protetoras do meio ambiente. É preciso voltar à apresentação inicial mais flexível deste princípio e introduzir a noção de exceção autorizada explicitamente.

O princípio objetiva induzir o poluidor a tratar as externalidades de sua produção. Para haver eficiência deste sistema, no entanto, este tratamento ou o emprego de tecnologias limpas devem custar menos do que a manutenção da poluição.

\section{Críticas e dificuldade de aplicação.}

Apesar da importância deste princípio na concretização da proteção ao meio ambiente, sua simplicidade é meramente aparente, escondendo problemas econômicos e jurídicos complexos. Sofre críticas severas e pertinentes e entre elas, destacam-se algumas. Primeiramente, surge o perigo de interpretar o princípio em estudo como uma equação econômica do tipo "pago, logo posso poluir" (BENJAMIN, 1993). É preciso cuidar para que não seja visto como um "alvará" para que aqueles que possuem poder econômico possam "comprar" o "direito de poluir". O intuito é a obrigação de repristinar o status quo violado pela atividade poluidora ou degradadora (ANTUNES, 1998). Ocorre, no entanto, que nem sempre é possível eliminar por completo o efeito poluidor, 
devendo neste caso, além do pagamento para tentar a melhor recomposição, cessar a atividade poluidora (CIRILLO, 1987).

Outra crítica refere-se ao custo. É sabido que o princípio visa imputar ao poluidor os custos sociais da poluição por ele causada, mas ocorre que estas "externalidades" podem ser repassadas aos consumidores pelos custos finais de produtos e serviços. O consumidor acaba pagando, indiretamente, pela poluição do produtor (MELLO 1976, BENJAMIN, 1993, DERANI, 1997).

Numa sociedade ideal, o adequado é a plena conscientização do produtor nos processos de sua atividade industrial com a não transmissão dos custos para o consumidor final, havendo plena aplicação de tecnologia limpa. Com o decorrer da evolução humana, baseada em aspectos sociais e não no lucro imediato, este repasse para o consumidor será absolutamente inválido e desnecessário.

No entanto, no momento neoliberal atual, este repasse faz do consumidor o pólo ativo e educador do mercado. Mas é necessário destacar que as realidades econômicas são diferentes nos diversos países capitalistas. Este repasse feito aos consumidores acompanha a "lei de mercado", mas no Brasil, é preciso haver completo respeito ao Código de Defesa do Consumidor (Lei 8.078 de 11 de setembro de 1990). Observa-se que no Brasil, país em desenvolvimento, o consumidor é um pólo fragilizado e é preciso muito cuidado para não fazer deste repasse de custos a completa devastação do pólo mais fraco e, o que é pior, justificada pelas bases conceituais do princípio poluidor-pagador. Em países em desenvolvimento, este repasse pode desestruturar o objetivo inicial do princípio poluidor-pagador, qual seja, o que força o produtor a dispor de tecnologias mais limpas.

O Código do Consumidor, de forma coerente, reconhece a vulnerabilidade do consumidor ( $\operatorname{art} .4^{\mathrm{O}}$, I) e expressa claramente em diversos artigos que o fabricante e o produtor respondem, independentemente da existência de culpa, pelas suas produções (art. 12, 14, entre outros). O objetivo do Código é explicitar o direito óbvio do consumidor de receber um produto de qualidade, sendo este um dever, e não uma opção do produtor. Portanto, a responsabilidade integral pela produção, que engloba o pagamento, a reparação dos danos e/ou a compensação dos bens lesados e a indenização às vítimas, permanece sempre com o produtor, não sendo isso uma opção.

O repasse de custos parciais ou totais (mais restrito que a responsabilidade), no entanto, se for efetivado no Brasil, pode ser feito, apenas e tão somente se houver ampla informação sobre este repasse no produto ou serviço ofertado (arts. $6^{\mathrm{O}} \mathrm{II}, 8^{\mathrm{O}}, 31$, entre outros). Portanto, para o repasse ser legal no Brasil, o consumidor precisa ter conhecimento pleno deste repasse nos rótulos e através de educação ambiental. Somente assim poder optar pelo produto advindo de tecnologias mais limpas e participar de forma 
democrática na mudança de comportamento do mercado. Qualquer repasse que esteja sendo feito hoje no Brasil e que não esteja sendo claramente informado nos rótulos é, portanto, ilegal e deve ser imediatamente reprimido pelos órgãos públicos e pela comunidade. Nos casos de produtos únicos e insubstituíveis, no entanto, este repasse ao consumidor é absolutamente inválido, pois o consumidor não tem como evitar consumilo. Ninguém é obrigado a consumir um produto único e ainda pagar pela poluição por ele produzida.

Outra dificuldade do princípio encontra-se no seu próprio conceito. É sabido que poluidor é o responsável pela produção e o que primeiro deve arcar com os custos de sua produção. No entanto, a origem da poluição não é sempre bem determinada. Exemplo disso são os fertilizantes ou pesticidas que causam poluição. A responsabilidade cabe tanto ao fabricante, que poderia fabricar produtos biodegradáveis, quanto ao agricultor que faz uso deles em quantidade excessiva (MARTINEZ Jr, 2000). No entanto, utiliza-se a regra de que é primeiramente responsável quem detém o poder econômico de decisão sobre o produto.

A poluição pode ser por energia, som, ou substâncias (art. $3^{0}$ da Lei 6.938/81, III, "alíneas d, e). Dentro destas substâncias, pode ser por ar, solo ou água. Uma grande dificuldade de aplicação do princípio em estudo é o fato de existirem diversas fontes não pontuais de poluição ou de difícil determinação. Exemplo disso é o caso da água da chuva que caía em regiões escandinavas e estavam contaminadas por gases sulfurosos de origem das regiões fortemente industrializadas do Continente Europeu (KISS, 1975). A responsabilização, nestes casos, torna-se extremamente difícil.

Outro problema é que os benefícios da produção limpa só são vistos em longo prazo, na saúde, meio ambiente e bem estar social. Em curto prazo, a exigência da prevenção através de um rígido princípio poluidor-pagador traz efeitos negativos para a capacidade competitiva do Estado nos mercados internacionais. Isso ocorre porque o produtor ou aumenta o preço do consumidor, ou pede ajuda estatal. Dos dois modos, portanto, haverá um aumento no custo final que acarretará uma desvantagem no mercado.

BULLINGER (1976) destaca que a política ambiental baseia-se nos efeitos externos da poluição que causam desequilíbrio para a vida humana. Não há completa execução do poluidor-pagador, pois alguns tipos de emissão podem ser aceitáveis, inclusive talvez lidando com desequilíbrios ainda desconhecidos que podem no futuro atingir proporções consideráveis. Portanto, observa-se que o poluidor-pagador lida com instrumentos de mercado e com a busca do bem estar social, mas não pode prever problemas ambientais futuros causados pelas atividades atuais por desconhecimento de seus efeitos. É preciso haver conscientização humana sobre as questões ambientais com visão global e em longo prazo, pois apenas a utilização de políticas de controle de poluição, como o poluidor-pagador, não são completamente eficazes. 
Outra grande dificuldade de aplicação do poluidor-pagador é a diferença econômica entre os países. Há autores que não concordam em tratar sem diferenciação econômica as relações estatais de controle de poluição. A Revista Nature (ENVIRONMENTAL, 1993) expressou este posicionamento, argumentando que alguns problemas ambientais são literalmente globais, mas há perigos que não são internacionais. Os países mais desenvolvidos repassam as tecnologias mais sujas para os países em desenvolvimento e, mesmo assim, estes devem pagar de forma igual pela poluição.

GOODLAND, DALY e SERAFY (1993) ressaltam que há diferença entre crescimento e desenvolvimento. Quando algo cresce, aumenta de tamanho; quando se desenvolve, fica qualitativamente melhor ou pelo menos diferente. Crescimento quantitativo e desenvolvimento qualitativo seguem leis diferentes entre os países, também a questão ambiental. Para eles, incentivos devem ser fixados para reduzir a produção de desperdício em todos os países, e não apenas o que fazer com este desperdício.

As diferentes realidades econômicas dos Estados, logicamente não justificariam a isenção de proteção ambiental por parte dos países menos favorecidos. Mas isto alerta para um paradoxo: a grande desigualdade que a igualdade entre os países geraria em termos econômicos e ambientais.

Estas dificuldades explicam por que o Direito Ambiental precisa ser tão dinâmico. As normas de poluição precisam levar em conta a região onde se situa a Bacia Hidrográfica, as atividades desenvolvidas no local e a variação anual de disponibilidade hídrica. Para isso, é necessário haver revisão constante das normas, para evitar que se tornem estanques e permitir que acompanhem a realidade e as peculiaridades da Bacia.

\section{O poluidor-pagador e sua responsabilidade jurídica no Brasil}

\section{a) Conceito, natureza jurídica}

A origem genérica da responsabilidade encontra-se no art. 159 do Código Civil brasileiro de 1.916. Nos seus arts. 554 e 555, observa-se as primeiras normas referentes ao uso nocivo da propriedade. A idéia de responsabilidade referindo-se especificamente à poluição, foi citada genericamente no Código de Águas (Decreto 24.643 de 10/7/34), nos arts 111 e 112. Estas disposições, no entanto, não englobavam as exigências modernas e necessárias de controle de efluentes. O Código dispõe algumas normas que coíbem a poluição hídrica, como o art. 110, que trata de seus casos de responsabilidade civil e penal (GRANZIERA, 1993).

A Lei da Política Nacional de Meio Ambiente (6.938/81) tem por objetivo a 
conservação, melhoria e recuperação da qualidade ambiental propícia à vida, assegurando o desenvolvimento sócio-econômico. $\mathrm{O}$ art. $3^{\mathrm{O}}$ da Lei apresenta os conceitos de meio ambiente, poluidor, poluição e degradação ambiental. A degradação ambiental é a alteração adversa das características do meio ambiente. Poluição é a degradação da qualidade ambiental resultante das atividades que direta ou indiretamente afetem desfavoravelmente a biota ou as condições sanitárias, prejudiquem a saúde, etc. (o rol do inciso é exemplificativo, inciso III). Por fim, poluidor é pessoa física ou jurídica de direito público ou privado responsável por atividade de degradação ambiental.

Apesar de a responsabilidade no Direito Civil brasileiro ser de cunho subjetivo e, portanto, vinculada à idéia de culpa ou dolo, na esfera ambiental, introduziuse a responsabilidade objetiva para a poluição (Lei 6.938/81, art. $141^{\circ}$ ). Isso foi um avanço, pois em se tratando de meio ambiente, não estamos nos reportando a um direito individual violado e sim a um direito difuso. A própria Constituição (art. 225), diz que "todos têm direito ao meio ambiente ecologicamente equilibrado, bem de uso comum do povo e essencial à sadia qualidade de vida [...]" (ALBUQUERQUE, 2000)

Pelo art. 14 da Lei 6.938/81, o poluidor é obrigado, "independentemente de culpa, a indenizar ou reparar os danos causados ao meio ambiente e a terceiros, afetados por sua atividade". Essa inovação foi resultante da atuação da Sociedade Brasileira de Direito do Meio Ambiente-SOBRADIMA, presidida por Paulo Affonso Leme Machado.

A atividade poluente acaba sendo uma apropriação pelo poluidor dos direitos de outrem, pois na realidade a emissão poluente representa um confisco do direito de alguém em respirar ar puro, beber água saudável e viver com tranqüilidade (MACHADO, 1994).

A responsabilidade objetiva, que independe de culpa (negligência, imperícia, imprudência) ou dolo (intenção do dano), resultou da dificuldade do lesado de provar esses elementos, especialmente devido às desigualdades econômicas entre o cidadão comum e as grandes empresas (PEREIRA apud FIORILLO e RODRIGUES, 1997).

O Direito não admite qualquer direito de prejudicar, lesar, poluir, degradar, ameaçar, causando dano ao meio ambiente no exercício de qualquer atividade autorizada ou permitida. O Direito assegura a atividade perigosa ou arriscada, que deve ser praticada diligentemente, mas não admite o dano dela decorrente. Com isso, a responsabilidade civil ambiental impõe novas técnicas tanto reparatórias para os danos causados quanto preventivas para os potenciais (CUSTÓDIO, 1996a).

A responsabilidade civil objetiva significa que quem danifica o meio ambiente tem o dever de repará-lo. Não importa a razão da degradação para que haja o dever de reparar. É contra o Direito enriquecer-se à custa da degradação ambiental (MACHADO, 2001). E isto vale tanto para quem polui quanto para quem despolui. 
É importante citar o Recurso Especial 287.127-SP, dado pelo Relator Ministro José Delgado, julgado em 6 de março de 2001, cujo acórdão diz que não há impossibilidade jurídica de obrigar-se um órgão de saneamento a não poluir um ribeirão. Este acórdão é um importante passo para exigir das Prefeituras Municipais o saneamento básico da população. Diversos Municípios alegam falta de verbas e de estrutura para criar e manter estação de tratamento de águas esgotos. A escusa não pode justificar a não implementação desse serviço público, principalmente por tratar-se de questão crucial e constitucional (art. 225), referente ao direito à sadia qualidade de vida.

\section{$\mathrm{Na}$ Comunidade Européia, o Livro Branco (COMISSÃO DAS} COMUNIDADES EUROPÉIAS, 2000) procurou avaliar diferentes opções de ação comunitária no domínio da responsabilidade ambiental. O objetivo foi analisar a melhor forma de permitir que o princípio poluidor-pagador atue para aumentar a prevenção dos danos ambientais. Uma ampla responsabilidade pelos danos causados ao ambiente leva à prevenção dos danos e à internalização dos custos ambientais. O Livro ressalta que a responsabilidade só é eficaz quando os poluidores podem ser identificados, os danos são quantificáveis e é possível demonstrar o nexo causal. Além disso, deve haver: critérios para avaliar e tratar os diferentes tipos de danos; introdução de um maior acesso à justiça nos casos de danos ambientais; coordenação com as convenções internacionais; trabalho conjunto com os mercados financeiros. Se a restauração não for tecnicamente possível, ou apenas for parcialmente, a avaliação dos recursos naturais tem de basear-se nos custos de soluções alternativas, de modo a restabelecer o nível de conservação da natureza e de biodiversidade incorporado na rede Natura 2000.

No Brasil, é conveniente ressaltar que a poluição ambiental ganhou um largo arcabouço jurídico no decorrer dos anos. Hoje, a poluição é punida civilmente (responsabilidade civil objetiva), administrativamente (atuação marcante dos órgãos de fiscalização), e penalmente (Lei 9.605/98 de Crimes Ambientais, no seu art. 54). Nos 3 casos há a possibilidade de multa por parte do responsável.

A responsabilidade é apurada das três formas objetivando fins diversos, daí provindo suas autonomias e a possibilidade de serem conjuntamente aplicadas, assim temos: responsabilidade penal, responsabilidade administrativa e responsabilidade civil. $\mathrm{Na}$ responsabilidade civil, o Brasil adotou, de forma bastante clara, um sistema que conjuga a responsabilidade civil objetiva e a reparação integral (art. $4^{\mathrm{O}}$, IV e $141^{\mathrm{o}}$ ). A vítima individual continua podendo pedir indenização por perdas e danos . Portanto, não foi excluído da responsabilidade ambiental a concessão de indenizações a terceiros (MACHADO, 2001). Como bem destacam FIORILLO e RODRIGUES (1997), não há como negar que a natureza da responsabilidade existente no poluidor-pagador é de cunho civil objetiva, com a prioridade da reparação específica do dano ambiental e a solidariedade para suportar os danos causados ao meio ambiente. 


\section{b) Abrangência e alcance da responsabilidade pela poluição no Brasil}

CUSTÓDIO (1996a) alerta que, a responsabilidade ambiental abrange não só a obrigação de recuperação ou restauração dos respectivos bens ambientais, como da saúde pública, das medidas sanitárias ou dos bens patrimoniais lesados, degradados ou descaracterizados, pois estas matérias também fazem parte da problemática ambiental.

Para FIORILLO e RODRIGUES (1997), o conceito de poluição diz menos do que o conceito de degradação ambiental, pois para que ocorra o primeiro, precisa haver uma "atividade", condicionando o conceito de poluição à atividade de uma pessoa física ou jurídica. Assim, o autor chega à conclusão de que não há um dever de indenizar em decorrência de uma degradação ambiental simplesmente. Há o dever quando esta degradação é resultante direta ou indiretamente da ação ou da omissão de uma pessoa. Portanto, precisa haver este plus da atividade no conceito de poluição. Portanto, a única alteração ambiental indenizável é a resultante de uma degradação ambiental vinculada a uma atividade de pessoa física ou jurídica. Além disso, ressaltam ainda que há independência das situações previstas no rol exemplificativo do artigo $3^{\mathrm{O}}$ III, bastando ser caracterizado um deles para haver poluição. Com isso, basta a configuração do dano à saúde e segurança pela atividade de uma empresa para evidenciar o seu dever objetivo em reparar o dano, independentemente de estar dentro dos padrões ambientais.

Ocorre, no entanto, que o alcance da responsabilidade sobre as atividades humanas degradadoras do meio ambiente é bastante amplo, abrangendo não somente os casos de efetiva concretização do dano, mas também, a sua potencialidade.

Para ressaltar a natureza e a abrangência da responsabilidade do poluidor também na potencialidade, MACHADO (2001) ressalta que a licença ambiental não libera o empreendedor licenciado de seu dever de reparar o dano ambiental. A licença retira o caráter de ilicitude administrativa do ato, mas não afasta a responsabilidade civil de reparar. A ausência de ilicitude administrativa irá impedir a Administração Pública de sancionar o prejuízo ambiental, mas nem por isso haverá irresponsabilidade civil.

Com isso, a lição de MACHADO (2001) é clara e inequívoca: a responsabilidade civil objetiva ambiental não se confunde com a figura da multa. Multa é decorrente de infração, ilicitude. Já no caso da responsabilidade civil, o poluidor deve reparar e/ou indenizar, mesmo nos casos de emissão que não ultrapassam os padrões fixados pelos órgãos ambientais. Ou responsabilidade objetiva do poluidor e, conseqüentemente, a aplicação do poluidor-pagador, ocorre independentemente da constatação de infrações.

MACHADO (2001) confirma este ensinamento, quando trata da nova cobrança pela utilização dos recursos hídricos. "Todos os lançamentos deverão ser cobrados, estejam ou não nos limites das normas de emissão, isto é, os lançamentos que 
observarem as normas de emissão pagarão, como também pagarão os lançamentos acima das normas de emissão." Portanto, mesmo a emissão autorizada pelos órgãos oficiais deve ser incluída no pagamento pelo uso das águas (Lei 9.433/97).

\section{c) Etimologia do termo e formas de ressarcimento ambiental}

FIORILLO e RODRIGUES (1997) destacam os objetivos do poluidorpagador, dando preferência pelo retorno ao status quo ante do que ao pagamento em pecúnia. Isto evita a comodidade das empresas em tratar os recursos naturais exclusivamente como bens econômicos. A necessidade de reparação em espécie objetiva conservar o meio ambiente e a sociedade como um todo, e atinge ainda mais o objetivo do poluidor-pagador do que o mero pagamento em dinheiro.

Realmente, a análise etimológica da palavra "pagador" não deixa dúvidas do significado do poluidor-pagador, tanto se analisado pela língua portuguesa quanto pela inglesa, na qual o termo foi inicialmente criado em 1972.

Em dicionários da língua portuguesa, podemos verifivar que pagar significa satisfazer o valor de; remunerar, gratificar, recompensar; retribuir, restituir na mesma espécie, sofrer um castigo ou pena (LIMA e BARROSO, 1943). Remunerar, gratificar, recompensar, do latim pacare (CUNHA, 1982).

Apesar de as definições serem claras ao abordar restituição da mesma espécie, é bom ressaltar que, tanto na língua inglesa (to pay) quanto na portuguesa (pagar), a origem da palavra em latim é a mesma: pacare. É possível, portanto, ir ao cerne do significado da palavra para não deixar dúvidas da abrangência em espécie do princípio e não a prevalência de pagamento em pecúnia.

"Paco, as, avi, atum, are, v. trans. (de pax). HIRT. Pacificar. Pacare mare a proedonibus. INSCR. Limpar o mar de piratas. - saltus. STAT. Restabelecer a segurança das florestas. - illam domum Jovis. LIV. Libertar aquella morada de Júpiter (o Capitolio). $\S$ CIC. JUST. Vencer, subjugar, sujeitar, submeter. § Fig. Arrotear, cultivar, amanhar, fertilizar" (SARAIVA, 1924).

Portanto, o significado da palavra abrange tanto o esforço para o restabelecimento ao status quo ante, quanto o pagamento em outra espécie ambiental e em pecúnia. No entanto, o bom senso nas questões ambientais leva à preferência de restabelecimento e pagamento em espécie quando isto é possível de ser efetivado. Somente assim será possível chegar-se aos reais objetivos do poluidor-pagador.

Convém destacar também quais tipos de poluição são abrangidas pela responsabilidade civil objetiva. A Lei $6.938 / 81$, no seu art. $3^{\circ}$, inciso III, traz o que se 
entende por poluição, e engloba em suas alíneas também a poluição por energia (som e calor), e a poluição estética (visual). Utilizando apenas como exemplo os períodos de propaganda eleitoral, já é possível observar diversas irregularidades onde não é aplicada a responsabilidade pela poluição. Poluição sonora que altera a rotina e o andamento do trabalho e prejudica o silêncio necessário perto de hospitais, além da poluição visual de imagens coladas em postes e outras localidades públicas sem autorização.

Outro exemplo de poluição visual observada diariamente e não responsabilizada com facilidade são as pichações (também citadas na Lei de Crimes Ambientais 9.605/98). Se houvesse uma efetiva aplicação do poluidor-pagador para estes casos, nossas cidades teriam outra imagem e a nossa cultura um respeito maior. Como destaca CUSTÓDIO (1996b), tanto os recursos naturais quanto os culturais são patrimônios ambientais e, o cumprimento de suas normas protetivas é urgente, para evitar o notório agravamento de sua degradação.

\section{Conclusões}

O princípio poluidor-pagador é bastante complexo e sujeito a diversas interpretações. A execução do princípio varia muito entre os diversos países, adequandose às realidades socioeconômicas de casa país.

O princípio poluidor-pagador não significa "pago, logo poluo". Sua rígida utilização objetiva a própria extinção da necessidade de sua utilização pelo reforço ao princípio da precaução. Para evitar essa distorção de sua natureza, sua realização deve ser diferenciada para não prejudicar alguns setores econômicos ou proteger outros. Este princípio é bastante dinâmico e deve ser aplicado em análise conjunta com os fatores ambientais e sociais e nunca apenas como fator econômico.

O termo poluidor significa, na base conceitual e na doutrina comparada do princípio em estudo, que quem detém o poder econômico de decisão sobre a fabricação do produto é o responsável e, conseqüentemente, o primeiro que deve pagar. No entanto, há a possibilidade, apenas quando houver ampla informação, de este valor ser repassado para o consumidor como forma de forçar o mercado a produzir tecnologia mais limpa por exigência da sociedade. Este repasse, no Brasil, apenas é válido e democrático quando o consumidor sabe a diferença que está pagando pela poluição e pode optar por comprá-lo ou não. Em respeito ao Código do Consumidor, no Brasil, todo e qualquer repasse feito sem a adequada informação do produto ao consumidor, é ilegal. Nos casos de produtos únicos e insubstituíveis, este repasse não é permitido por haver impossibilidade de escolha por parte do consumidor.

Etimologicamente demonstrado, o termo pagador não envolve necessariamente pagamento em pecúnia. É retorno ao status quo ante, reparação da 
mesma espécie, recompensa, compensação e pagamento em dinheiro. Pela natureza e objetivos do poluidor-pagador, dá-se preferência por esta mesma ordem. E preferência ainda maior pelo princípio da precaução, anteriormente e conjuntamente ao poluidorpagador.

A doutrina contemporânea tem entendido que o poluidor-pagador envolve não mais somente os custos de controle de poluição, medidas de prevenção e/ou restauração exigidos pela autoridade pública, mas também: i) a possibilidade de ajuda financeira em esforços necessários em escala mundial; ii) a inclusão do custo do dano residual em casos de danos significantes; iii) a inclusão de medidas e controle de poluição acidental, arcando com o custo de "medidas razoáveis" determinadas por cada país; iv) a possibilidade de o poluidor compartilhar seus custos através de seguros.

O sistema adotado no Brasil para o princípio poluidor-pagador é o da responsabilidade objetiva e da reparação integral do dano. Mesmo nos casos de emissão permitida há a incidência do princípio em estudo, bem como a possibilidade de pagamento a vítimas de poluição. Isto demonstra que o Brasil utiliza a moderna concepção do poluidor-pagador adotada pela doutrina internacional.

Com a aplicação da responsabilidade objetiva, estão incluídas não somente a poluição material, mas também a sonora, visual e estética e a cultural, nas mesmas formas de ressarcimento e exigências legais, de acordo com a Lei 6.938/81.

O poluidor-pagador não se confunde com a figura da multa, pois envolve tanto atos ilícitos quanto ato lícitos,. Deve ser utilizado através de meios judiciais e administrativos bem como por qualquer meio legalmente possível de prevenção e controle da poluição.

\section{REFERENCIAS}

ALBUQUERQUE, F. S. A responsabilidade civil e o princípio do poluidorpagador.Jurisforma Disponível em: $<\mathrm{http}: /$ www.jurisforma.com.br/notas/0040.shtml>. Acesso em: 17 dez. 2000.

ALMEIDA, L. T. Política ambiental: uma análise econômica. Campinas: Papirus, 1998. 192 p. ISBN 85-308-0524-0.

ANTUNES, P. B. Direito ambiental. 2 ed. Rio de Janeiro: Lumen Juris, 1998. 505 p.

BENJAMIN, A. H. O princípio poluidor-pagador e a reparação do dano ambiental. In: . Dano ambiental: prevenção, reparação e regressão. São Paulo: Revista dos Tribunais, 1993. p.226-236. 
BULLINGER, M. et al. The Polluter pays principle and its instruments: an interdisciplinary investigation. Modern Law and Society, Tübingen, v. 9, n. 2, p. 195-203, 1976.

CIRILLO, G. Ambiente, inquinamento ed illecito nel diritto internazionale. In: CÉSARO, E. Danno ambientale e tutela giuridica. Padova: CEDAM, 1987. p.101-107.

COMISSÃO DAS COMUNIDADES EUROPÉIAS. Livro branco da responsabilidade ambiental. Comissão das Comunidades Européias. Disponível em: $<$ http://europa.eu.int/comm/environment/liability/el_full_pt.pdf $>$. Acesso em: 16 dez. 2000.

CUNHA, A. G. (Ed.). Dicionário Etimológico Nova Fronteira da Língua Portuguesa: português/português. Rio de Janeiro: Nova Fronteira, 1982. 839p.

CUSTÓDIO, H. B. Uma introdução à responsabilidade civil por dano ambiental. Revista de Direito Civil: Imobiliário, Agrário e empresarial, São Paulo, n. 75, p. 69-80, jan./mar. 1996a.

. Legislação ambiental no Brasil. Revista de Direito Civil: Imobiliário, Agrário e empresarial, São Paulo, n. 76, p. 56-71, abri./jun., 1996 b.

DERANI, C. Direito ambiental econômico. São Paulo: Max Limonad, 1997. 297p.

ENVIRONMENT DIRECTORATE. The polluter pays principle. OECD Analyses and recommendations. Paris: OECD, 1992. 49f. Disponível em: <www.oecd.org>. Acesso em: 16 mar. 2000.

ENVIRONMENTAL: protection or imperialism? Nature, London, v. 363, p. 657658,1993 .

FIORILLO, C. A. P.; RODRIGUEZ, M. A. Manual de direito ambiental e legislação aplicável. São Paulo: Max Limonad, 1997. 577p.

GOODLAND, R. J. A.; DALY, H. E.; SERAFY, S. E. The urgent need for rapid transition to global environmental sustainability. Environmental Conservation, New York, v. 20, n. 4, p. 297-309, 1993.

GRANZIERA, M. L.M. Direito de águas e meio ambiente. São Paulo: Cone, 1993. 136 p.

KISS, A. C. Los principios generales del derecho del medio ambiente. Vitoria: Universidad de Valladoid, 1975. 118p.

LiMA, H.; BARroso, G. Pequeno Dicionário Brasileiro da Língua Portuguesa: 
português/português. São Paulo, Civilização Brasileira, 1943. 1039p.

MACHADO, P. A. L. Hidrelétricas - Responsabilidade jurídica-ambiental. Estudos de Direito Ambiental. São Paulo: Malheiros. p. 93-109. 1994.

. Direito ambiental brasileiro. 9.ed. rev. atual. ampl. São Paulo: Malheiros, 2001. 1031 p. ISBN 85-7420-166-9.

MARTINEZ JUNIOR, F. Princípio usuário-pagador e desenvolvimento sustentável. In: THAME, A. C.M. (Org.). A cobrança pelo uso da água. São Paulo: Melhoramentos, 2000. p. 115-124.

MELLO, M. J. M. Economia y medio ambiente: Las consecuencias economicas de la deterioracion ambiental. Montevideo: Ministério de las Relaciones Exteriores de la República del Uruguay, 1976.

OECD. The polluter pays principle: definition, analysis, implementation. Paris, 1975. $117 \mathrm{p}$.

SMETS, H. Les subventions pour une meilleure protection de l'environnement. Environmental Policy and Law, North-Holland, v. 27, n. 4, p. 270-275. 1997.

SARAIVA, F. R. S. Novíssimo Diccionario Latino-Portuguez: etymologico, prosodico, historico, geographico, mythologico, biographico, etc: latim/português, português/latim. Rio de Janeiro: Garnier, 1924. 1297p. 